\title{
REVIEW
}

\section{Diagnosis, evaluation, and management of acute kidney injury: a KDIGO summary (Part 1)}

\author{
John A Kellum*1 and Norbert Lameire², for the KDIGO AKI Guideline Work Group ${ }^{3}$
}

\begin{abstract}
Acute kidney injury (AKI) is a common and serious problem affecting millions and causing death and disability for many. In 2012, Kidney Disease: Improving Global Outcomes completed the first ever, international, multidisciplinary, clinical practice guideline for AKI. The guideline is based on evidence review and appraisal, and covers AKI definition, risk assessment, evaluation, prevention, and treatment. In this review we summarize key aspects of the guideline including definition and staging of AKI, as well as evaluation and nondialytic management. Contrast-induced AKI and management of renal replacement therapy will be addressed in a separate review. Treatment recommendations are based on systematic reviews of relevant trials. Appraisal of the quality of the evidence and the strength of recommendations followed the Grading of Recommendations Assessment, Development and Evaluation approach. Limitations of the evidence are discussed and a detailed rationale for each recommendation is provided.
\end{abstract}

\section{Introduction}

Acute kidney injury (AKI) is common and imposes a heavy burden of illness (morbidity and mortality). Furthermore, the costs of care for patients with AKI are high and there is considerable variability in practice. AKI is amenable to prevention, early detection and treatment. Clinical practice guidelines in the field thus have the potential to reduce variations, improve outcomes, and reduce costs.

Care of the critically ill patient with AKI requires coordination of care across multiple disciplines in a variety of settings. This year, Kidney Disease: Improving Global

\footnotetext{
*Correspondence: kellumja@upmc.edu

'The CRISMA Center, Department of Critical Care Medicine, 604 Scaife Hall,

University of Pittsburgh School of Medicine, Pittsburgh, PA 15261, USA
}

Full list of author information is available at the end of the article
Outcomes (KDIGO), a nonprofit foundation, has published the first international, interdisciplinary clinical practice guideline on AKI [1], which is also available in its entirety on the KDIGO website [2]. We present here a shortened version of the guideline focusing on definitions, risk assessment, evaluation, and nondialytic management; we also provide additional rationale and commentary for those recommendation statements that most directly impact the practice of critical care.

\section{Methods}

A complete and detailed description of the methods can been found online [3]. The KDIGO Co-Chairs appointed two Co-Chairs of the Work Group, who then assembled experts in several domains (nephrology, critical care medicine, internal medicine, pediatrics, cardiology, radiology, infectious diseases, and epidemiology). The Evidence Review Team at Tufts Medical Center, Boston, MA, USA consisted of physician-methodologists with expertise in nephrology and internal medicine, and research associates and assistants.

The evidence selection, appraisal, and presentation have followed methodology previously described in KDIGO clinical practice guidelines [4]. Work Group members reviewed all retrieved relevant articles, data extraction forms, summary tables, and evidence profiles for accuracy and completeness. The four major topic areas of interest for AKI included: definition and classification; prevention; pharmacologic treatment; and renal replacement therapy (RRT). Populations of interest were those at risk for AKI (including those after intravascular contrast-media exposure, aminoglycosides, and amphotericin), and those with AKI or at risk for AKI with a focus on patients with sepsis or trauma, receiving critical care, or undergoing cardiothoracic surgery. We excluded studies on AKI from rhabdomyolysis, specific infections, and poisoning or drug overdose. Overall, we screened 18,385 citations.

\section{Outcome selection, judgments, values, and preferences} We limited outcomes to those important for decisionmaking, including development of AKI, need for or dependence on RRT, and all-cause mortality. When 
weighting the evidence across different outcomes, we selected as the crucial outcome that which weighed most heavily in the assessment of the overall quality of evidence. Values and preferences articulated by the Work Group included: a desire to be inclusive in terms of meeting criteria for AKI; a progressive approach to risk and cost such that, as severity increased, the group put greater value on possible effectiveness of strategies, but maintained high value for avoidance of harm; and intent to guide practice but not limit future research.

\section{Grading the quality of evidence and the strength of recommendations}

The grading approach followed in this guideline and the wording of each recommendation are adopted from the Grading of Recommendations Assessment, Development and Evaluation system $[4,5]$. The strength of each recommendation is rated as level 1 (strong) or level 2 (weak or discretionary). In addition, each statement is assigned a grade for the quality of the supporting evidence: A (high), B (moderate), C (low), or D (very low). Furthermore, on topics that cannot be subjected to systematic evidence review, the Work Group issued statements that are not graded which hopefully will provide general guidance that is based on clinical experience.

The Grading of Recommendations Assessment, Development and Evaluation system is best suited to evaluate evidence on comparative effectiveness. Some of our most important guideline topics involve diagnosis and staging of AKI, and here the Work Group chose to provide ungraded statements. These statements are indirectly supported by evidence on risk relationships and resulted from unanimous consensus of the Work Group and should not be viewed as weaker than graded recommendations.

\section{Recommendations and rationale}

The Work Group developed 61 graded recommendation statements and 26 ungraded statements. The six major domains are: (A) definition and staging; (B) risk assessment; (C) evaluation and general management; (D) prevention and treatment; (E) contrast-induced AKI; and (F) RRT for AKI. Domains (A) through (D) are presented here while domains (E) and (F) are presented in Lameire et al. immediately following this review.

\section{A. Definition and staging of AKI}

AKI is defined by an abrupt decrease in kidney function that includes, but is not limited to, acute renal failure. AKI is a broad clinical syndrome encompassing various etiologies, including pre-renal azotemia, acute tubular necrosis, acute interstitial nephritis, acute glomerular and vasculitic renal diseases, and acute postrenal obstructive nephropathy. More than one of these conditions may coexist in the same patient and epidemiological evidence supports the notion that even mild, reversible AKI has important clinical consequences, including increased risk of death $[6,7]$. AKI can thus be considered more like acute lung injury or acute coronary syndrome. Furthermore, because the manifestations and clinical consequences of AKI can be quite similar (even indistinguishable) regardless of whether the etiology is predominantly within the kidney or predominantly from outside stresses on the kidney, the syndrome of AKI encompasses both direct injury to the kidney as well as acute impairment of function.

The Acute Dialysis Quality Initiative group developed the Risk, Injury, Failure; Loss and End-stage kidney disease (RIFLE) system for diagnosis and classification of a broad range of acute impairment of kidney function through a broad consensus of experts [8]. Studies totaling over 0.5 million patients from around the world have shown that AKI defined by RIFLE is associated with decreased survival and that increasing RIFLE stage leads to increased risk of death [9-14].

More recently, the Acute Kidney Injury Network endorsed the RIFLE criteria with a modification to include small changes in serum creatinine $(\mathrm{SCr})(\geq 0.3 \mathrm{mg} / \mathrm{dl}$ or $26.5 \mu \mathrm{mol} / \mathrm{l})$ when they occur within a 48 -hour period [15]. Two recent studies examining large databases in the USA [12] and Europe [13] validated these modified criteria. Thakar and colleagues found that increased severity of AKI was associated with an increased risk of death independent of comorbidity [12]. Patients with stage 1 AKI $(\geq 0.3 \mathrm{mg} / \mathrm{dl}$ or $26.5 \mu \mathrm{mol} / \mathrm{l}$ increase in $\mathrm{SCr}$ but less than a twofold increase) had an odds ratio of 2.2; in patients with stage 2 AKI (corresponding to RIFLE-I) there was an odds ratio of 6.1; and in stage 3 AKI patients (RIFLE-F) the odds ratio was 8.6 for hospital mortality. An additional modification to the RIFLE criteria has been proposed for pediatric patients in order to better classify small children with acute-on-chronic disease [16].

Unfortunately, the existing criteria - while useful and widely validated - are still limited. First, despite efforts to standardize the definition and classification of AKI, there is still inconsistency in application [10,11]. A minority of studies have included urinary output criteria despite their apparent ability to identify additional cases $[13,17]$ and many studies have excluded patients whose initial SCr is already elevated. Preliminary data suggest that roughly one-third of AKI cases are community acquired [18] and many cases may be missed by limiting analysis to documented increases in SCr. Indeed, the majority of cases of AKI in the developing world are likely to be community acquired. Few studies can thus provide accurate incidence data. An additional problem relates to the limitations of SCr and urine output for detecting AKI. In the future, biomarkers of renal cell injury may identify 
Table 1. Staging of acute kidney injury

\begin{tabular}{|c|c|c|}
\hline Stage & Serum creatinine & Urine output \\
\hline 1 & 1.5 to 1.9 times baseline or $\geq 0.3 \mathrm{mg} / \mathrm{dl}(\geq 26.5 \mu \mathrm{mol} / \mathrm{l})$ increase & $<0.5 \mathrm{ml} / \mathrm{kg} /$ hour for 6 to 12 hours \\
\hline 2 & 2.0 to 2.9 times baseline & $<0.5 \mathrm{ml} / \mathrm{kg} /$ hour for $\geq 12$ hours \\
\hline 3 & $\begin{array}{l}3.0 \text { times baseline or increase in serum creatinine to } \geq 4.0 \mathrm{mg} / \mathrm{dl}(\geq 353.6 \mu \mathrm{mol} / \mathrm{l}) \text { or } \\
\text { initiation of renal replacement therapy or in patients }<18 \text { years a decrease in eGFR to } \\
<35 \mathrm{ml} / \mathrm{minute} \text { per } 1.73 \mathrm{~m}^{2}\end{array}$ & $<0.3 \mathrm{ml} / \mathrm{kg} / \mathrm{hour}$ for $\geq 24$ hours or anuria for $\geq 12$ hours \\
\hline
\end{tabular}

eGFR, estimated glomerular filtration rate.

additional patients with AKI and may identify the majority of patients at an earlier stage. These concerns notwithstanding, and in view of the available evidence, the Work Group accepted the existing criteria for the diagnosis and staging of AKI and proposed a single definition of AKI that should be useful for practice, research, and public health.

A1: AKI is defined as any of the following (not graded):

- increase in SCr by $\geq 0.3 \mathrm{mg} / \mathrm{dl}(\geq 26.5 \mu \mathrm{mol} / \mathrm{l})$ within 48 hours; or

- increase in SCr to $\geq 1.5$ times baseline, which is known or presumed to have occurred within the prior 7 days; or

- urine volume $<0.5 \mathrm{ml} / \mathbf{k g} /$ hour for 6 hours.

A2: AKI is staged for severity according to the criteria presented in Table 1 (not graded).

A3: The cause of AKI should be determined whenever possible (not graded).

\section{B. Risk assessment}

There are many types of exposure that may cause AKI. However, the chances of developing AKI after exposure to the same insult depend on a number of susceptibility factors that vary widely from individual to individual. Our understanding of susceptibility factors is based on many observational studies that address different settings with regards to the type, severity, duration, and multiplicity of insults. While this heterogeneity provides insight into some susceptibility factors that are common across various populations, the generalizability of results from one particular setting to the next is uncertain.

It is important to screen patients who have undergone an exposure (Table 2) and to continue monitoring highrisk patients until the risk has subsided. Exact intervals for checking SCr and for which individuals' urine output should be monitored remain matters of clinical judgment; however, as a general rule, high-risk in-patients should have $\mathrm{SCr}$ measured at least daily and more frequently after an exposure, and critically ill patients should undergo urine output monitoring. This will necessitate urinary bladder catheterization in many cases, and the risks of infection should also be considered in the monitoring plan. Many opportunities for prevention and
Table 2. Causes of acute kidney injury: exposures and susceptibilities for nonspecific acute kidney injury

\begin{tabular}{ll}
\hline Exposure & Susceptibility \\
\hline Sepsis & Dehydration or volume depletion \\
Critical illness & Advanced age \\
Circulatory shock & Female gender \\
Burns & Black race \\
Trauma & Chronic kidney disease \\
Cardiac surgery (especially with & Chronic diseases (heart, lung, liver) \\
cardiopulmonary bypass) & \\
Major noncardiac surgery & Diabetes mellitus \\
Nephrotoxic drugs & Cancer \\
Radiocontrast agents & Anemia \\
Poisonous plants and animals & \\
\hline
\end{tabular}

earlier recognition of AKI at emergency admissions may be missed. For example, a recent clinical practice assessment of emergency admissions in the UK highlights missed opportunities for prevention and earlier recognition of AKI [19].

B1: We recommend that patients be stratified for risk of AKI according to their susceptibilities and exposures (Grade 1B).

B2: Manage patients according to their susceptibilities and exposures to reduce the risk of AKI (see relevant guideline sections) (not graded).

B3: Test patients at increased risk for AKI with measurements of $\mathrm{SCr}$ and urine output to detect AKI (not graded). Individualize frequency and duration of monitoring based on patient risk and clinical course (not graded).

\section{Evaluation and general management}

AKI is one of a number of conditions that affect kidney structure and function. Because the manifestations and clinical consequences of AKI can be quite similar (even indistinguishable) regardless of whether the etiology is predominantly within the kidney or predominantly from outside stresses on the kidney, the syndrome of AKI encompasses both direct injury to the kidney as well as acute impairment of function. Since treatments of AKI are dependent to a large degree on the underlying etiology, this guideline focuses on specific diagnostic 
approaches (Figure 1). However, since general therapeutic and monitoring recommendations can be made regarding all forms of AKI, our approach will be to begin with general measures (Figure 2).

The clinical evaluation of AKI includes a careful history and thorough physical examination. Drug history should include over-the-counter formulations and herbal remedies or recreational drugs. The social history should include exposure to tropical diseases, and physical examination should include evaluation of fluid status, signs for acute and chronic heart failure, and infection. Measurement of cardiac function and intra-abdominal pressure should be considered in the appropriate clinical context. Laboratory parameters - including SCr, blood urea nitrogen, and electrolytes, complete blood count and differential - should be obtained. Urine analysis and microscopic examination as well as urinary chemistries may be helpful in determining the underlying cause of AKI. Imaging tests, especially ultrasound, are important components of the evaluation for patients with AKI. Finally, a number of biomarkers of functional change and cellular damage are under evaluation for early diagnosis of AKI, risk assessment for AKI, and prognosis of AKI. Although an evidence-based analysis of the role of biomarkers was beyond the scope of this guideline, recent work suggests in particular that the prognostic utility of newer urinary biomarkers - including neutrophil gelatinase-associated lipocalin, kidney injury molecule-1, and IL-18 - added to urine microscopic examination is significantly higher over clinical assessment alone [20].

Because the stage of AKI has clearly been shown to correlate with short-term $[6,7,11,13]$ and even longerterm outcomes [21], it is advisable to tailor management to AKI stage. Figure 2 lists a set of actions that should be considered for patients with AKI. Note that for patients at increased risk, these actions begin even before AKI is diagnosed. Note also that management and diagnostic steps are both included in this figure. This is because response to therapy is an important part of the diagnostic approach. There are few specific tests to establish the etiology of AKI. However, a patient's response to treatment (for example, discontinuation of a possible nephrotoxic agent) provides important information as to the diagnosis.

C1: Evaluate patients with AKI promptly to determine the cause, with special attention to reversible causes (not graded).

C2: Monitor patients with AKI with measurements of $\mathrm{SCr}$ and urine output to stage the severity, according to Recommendation A2 (not graded).

C3: Manage patients with AKI according to the stage (see Figure 2) and cause (not graded).

C4: Evaluate patients 3 months after AKI for resolution, new onset, or worsening of

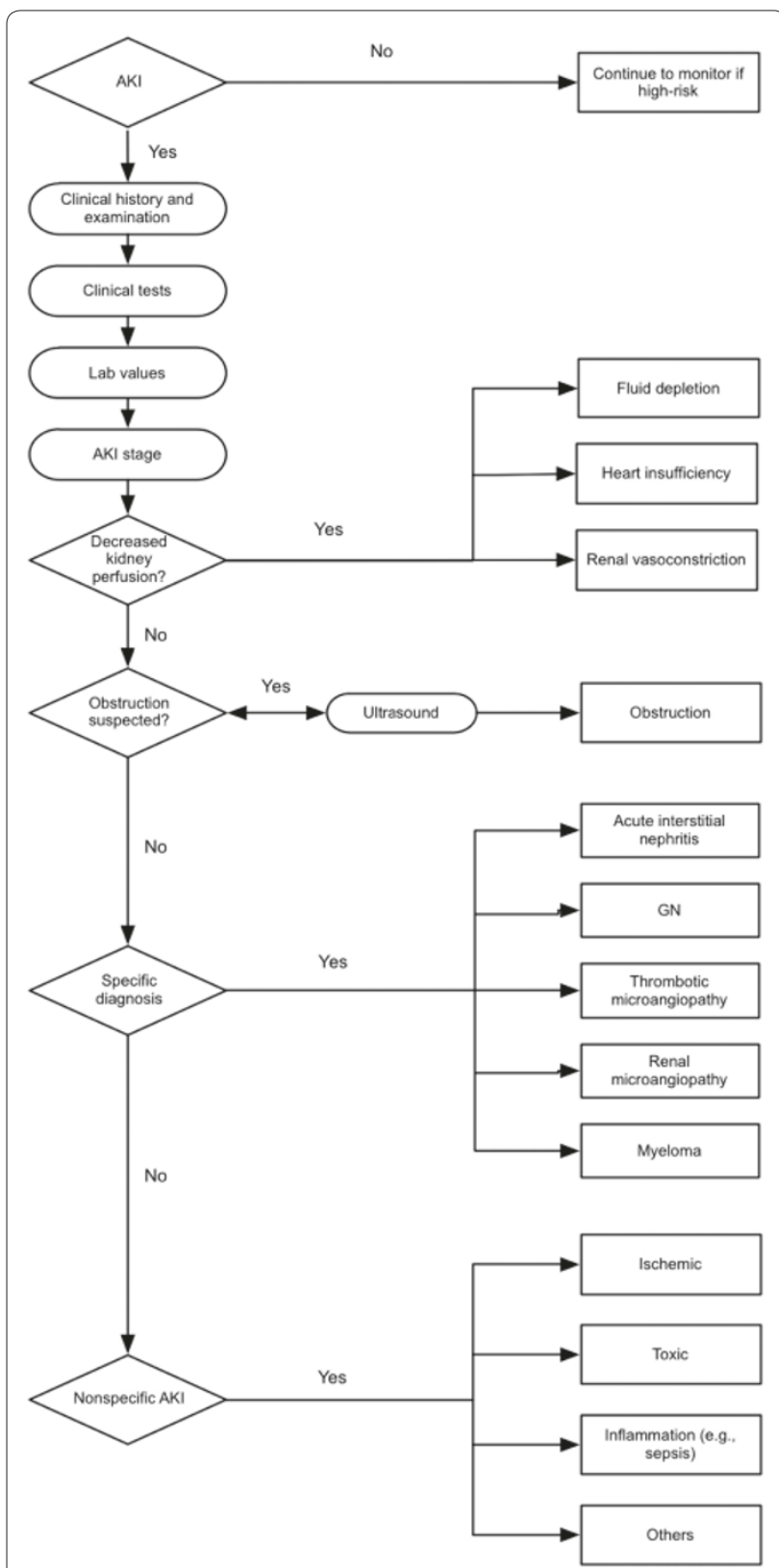

Figure 1. Evaluation of acute kidney injury. AKI, acute kidney injury; GN, glomerulonephritis.

pre-existing chronic kidney disease (CKD) (not graded).

- If patients have CKD, manage these patients as detailed in the Kidney Disease Outcomes Quality Initiative chronic kidney disease (CKD) guideline (Guidelines 7 to 15) (not graded).

- If patients do not have CKD, consider them to be at increased risk for CKD and care for them as detailed in the Kidney Disease Outcomes Quality Initiative CKD 


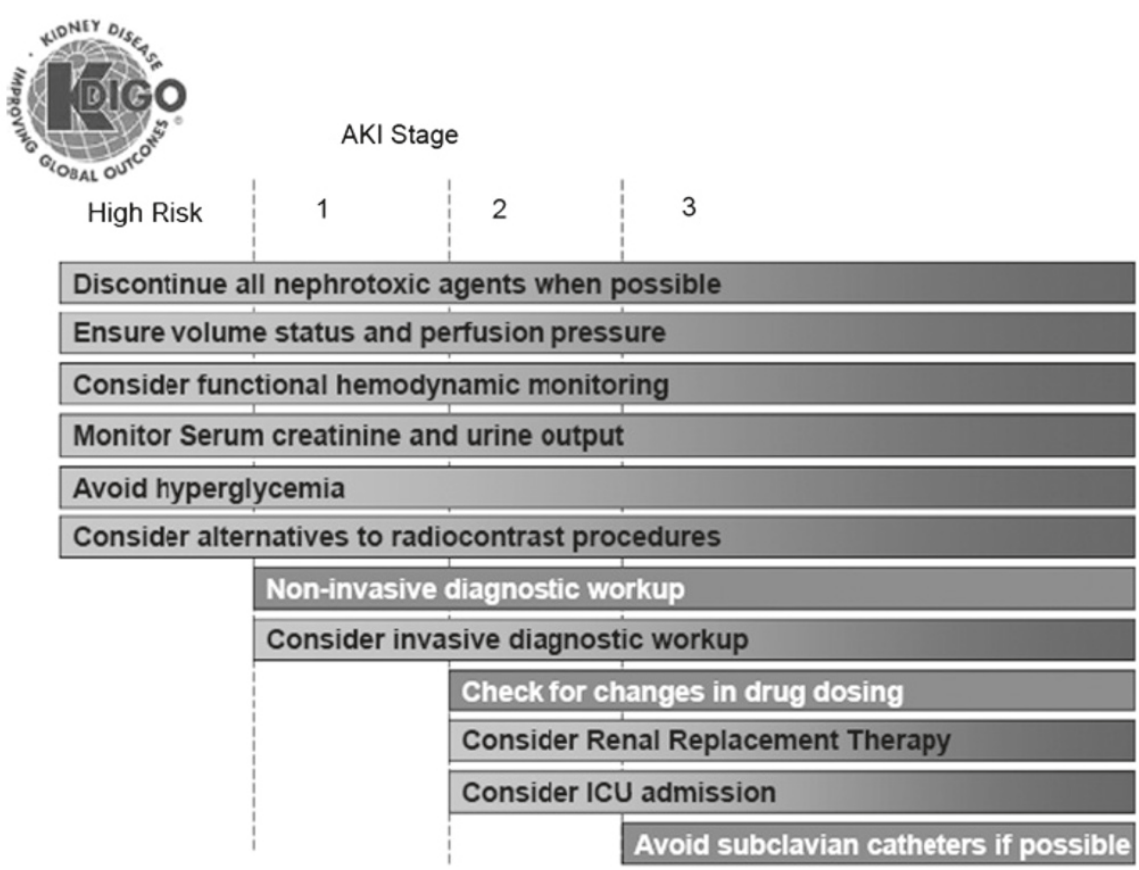

Figure 2. Stage-based management of acute kidney injury. Shading of boxes indicates priority of action: solid shading, actions that are equally appropriate at all stages; graded shading, increasing priority as intensity increases. AKI, acute kidney injury.

Guideline 3 for patients at increased risk for CKD (not graded).

\section{Prevention and treatment of AKI Fluids and vasopressors}

Despite the recognition of volume depletion as an important risk factor for AKI, there have been no randomized controlled trials (RCTs) that directly evaluated the role of fluids versus placebo in the prevention of AKI, except in the field of contrast-induced AKI (see Lameire et al. immediately following this review). While fluid resuscitation is widely believed to be protective, large multicenter studies have also shown that a positive fluid balance is associated with increased 60-day mortality [22-24].

Results of the Saline vs. Albumin Fluid Evaluation study - a RCT comparing 4\% human albumin in $0.9 \%$ saline with isotonic saline in ICU patients - indicated that albumin is safe, albeit no more effective than isotonic saline for fluid resuscitation [25]. The study demonstrated no difference in need for and duration of RRT [25]. Very few patients in the trial received large volume fluid resuscitation (>5 l) and thus the results may not be applicable to all patients.

Hydroxyethylstarch (HES) is a widely used, relatively inexpensive alternative to human albumin for correcting hypovolemia. A recent Cochrane review concluded that there is no evidence that resuscitation with colloids, instead of crystalloids, reduces the risk of death in patients with trauma, burns, or following surgery [26]. In addition to some negative effects on coagulation, particularly with older forms of HES, development of renal dysfunction has been a concern associated with the use of mainly hypertonic HES. A recent meta-analysis described 11 randomized trials with a total of 1,220 patients: seven trials evaluating hyperoncotic albumin and four trials evaluating hyperoncotic starch [27]. Hyperoncotic albumin decreased the odds of AKI by $76 \%$ while hyperoncotic starch increased those odds by $92 \%$ (odds ratio $(\mathrm{OR})=1.92 ; 95 \%$ confidence interval $(\mathrm{CI})=1.31$ to 2.81; $P=0.0008)$. Parallel effects on mortality were observed. The renal effects of hyperoncotic colloid solutions appeared to be colloid specific, with albumin displaying renoprotection and hyperoncotic starch showing nephrotoxicity. A 7,000-patient study comparing $6 \%$ HES 130/0.4 in saline with saline alone was scheduled to begin in Australia and New Zealand in 2010. This study will provide further high-quality data to help guide clinical practice [28].

The use of isotonic saline as the standard of care for intravascular volume expansion to prevent or treat AKI is thus based upon the lack of clear evidence that colloids are superior for this purpose, along with some evidence that specific colloids may cause AKI, in addition to their higher costs. It is acknowledged that colloids may be chosen in some patients to aid in reaching resuscitation goals, or to avoid excessive fluid administration in patients requiring large volume resuscitation, or in 
specific patient subsets (for example, a cirrhotic patient with spontaneous peritonitis, or in burns). Similarly, although hypotonic or hypertonic crystalloids may be used in specific clinical scenarios, the choice of crystalloid with altered tonicity is generally dictated by goals other than intravascular volume expansion (for example, hypernatremia or hyponatremia). In addition, isotonic saline solution contains $154 \mathrm{mmol} / \mathrm{l}$ chloride and when administration in large volumes will result in relative or absolute hyperchloremia (for a review, see Kaplan and Kellum [29]). Buffered salt solutions approximate physiological chloride concentrations and cause less acid-base disturbances and other side effects associated with hyperchloremia. Whether the use of buffered solutions results in better clinical outcomes, however, is uncertain. Once the intravascular volume has been optimized, it is not known which vasopressor agent is most effective for management of shock in general, or for the kidney specifically. A large RCT comparing dopamine with norepinephrine as the initial vasopressor in patients with shock showed no significant differences between groups with regard to renal function or mortality. However, there were more arrhythmic events among the patients treated with dopamine [30]. Vasopressin is gaining popularity in the treatment of shock refractory to norepinephrine [31]. Compared with norepinephrine, vasopressin increases blood pressure and enhances diuresis, but has not been proven to enhance survival or to reduce the need for RRT [32]. Although there is some suggestion that vasopressin may reduce progression to renal failure and mortality in patients with septic shock [33], the Work Group concluded that current clinical data are insufficient to recommend one vasoactive agent over another in preventing AKI, but emphasized that vasoactive agents should not be withheld from patients with vasomotor shock over concern for kidney perfusion. Indeed, appropriate use of vasoactive agents can improve kidney perfusion in volume-resuscitated patients with vasomotor shock.

While the risks and benefits of so-called early goaldirected therapy are unclear and three large trials are underway in the USA, Australia and the UK, there is some evidence that protocolized resuscitation may be better than standard care. A recent meta-analysis concluded that protocolized therapies (regardless of the protocol) with specific physiological goals can significantly reduce postoperative AKI [34]. A problem in interpreting these studies is the lack of standardized hemodynamic and tissue oxygenation targets and management strategies used to verify the efficacy of these measures over standard perioperative care. A heterogeneous collection of study populations, types of surgical procedures, monitoring methods, and treatment strategies comprise this recent meta-analysis [34]. The basic strategy of goal-directed therapy to prevent AKI in the perioperative period is based on protocols that avoid hypotension, optimize oxygen delivery, and include careful fluid management, vasopressors when indicated, and inotropic agents and blood products if needed [34]. Given the limitations of the current studies and the lack of comparative effectiveness studies of individual protocols, we can only conclude that protocols for resuscitation in the setting of septic shock and high-risk surgery appear to be superior to no protocol.

D1: In the absence of hemorrhagic shock, we suggest using isotonic crystalloids rather than colloids (albumin or starches) as initial management for expansion of intravascular volume in patients at risk for AKI or with AKI (Grade 2B).

D2: We recommend the use of vasopressors in conjunction with fluids in patients with vasomotor shock with, or at risk for, AKI (Grade 1C).

D3: We suggest using protocol-based management of hemodynamic and oxygenation parameters to prevent development or worsening of AKI in high-risk patients in the perioperative setting (Grade 2C) or in patients with septic shock (Grade 2C).

\section{Nutrition and glycemic control}

Pooled analyses of early multicenter studies have failed to confirm the early observations of beneficial effects of intensive insulin therapy on renal function; the risk of hypoglycemia with this approach is significant, and the survival benefits of intensive insulin therapy are in doubt $[35,36]$. The international Normoglycemia in Intensive Care Evaluation and Survival Using Glucose Algorithm Regulation study found a 90 -day mortality of $27.5 \%$ in the intensive insulin therapy group (target blood glucose range 81 to $108 \mathrm{mg} / \mathrm{dl}(4.5$ to $6.0 \mathrm{mmol} / \mathrm{l})$ ) and a 90-day mortality of $24.9 \%$ in the conventional glucose control (target $\leq 180 \mathrm{mg} / \mathrm{dl}(\leq 10.0 \mathrm{mmol} / \mathrm{l})$ ) (OR for intensive control $=1.14 ; 95 \% \mathrm{CI}=1.02$ to $1.28 ; P=0.02$ ) [37]. The treatment effect did not differ significantly between surgical patients and medical patients. There was no significant difference between the two treatment groups in incidence of new RRT ( $15.4 \%$ vs. $14.5 \%)$. Severe hypoglycemia (blood glucose level $\leq 40 \mathrm{mg} / \mathrm{dl}(\leq 2.2 \mathrm{mmol} / \mathrm{l})$ ) was reported in $6.8 \%$ in the intensive-control group and in $0.5 \%$ in the conventional-control group $(P<0.001)$. Considering the balance between potential benefits and harm, the Work Group suggests using insulin for preventing severe hyperglycemia in critically ill patients but in view of the danger of potentially serious hypoglycemia, we suggest that the average blood glucose should not exceed $149 \mathrm{mg} / \mathrm{dl}(8.3 \mathrm{mmol} / \mathrm{l})$, but that 
insulin therapy should not be used to lower blood glucose to $<110 \mathrm{mg} / \mathrm{dl}(6.1 \mathrm{mmol} / \mathrm{l})$. The Work Group recognizes that these thresholds have never directly been examined in RCTs but are interpolated from the comparisons so far tested in the trials.

Several expert panels have developed clinical practice guidelines for the nutritional management of patients with AKI, whether treated with or without RRT [38-42]. Observations in critically ill patients provide a rationale to maintain a total energy intake of at least $20 \mathrm{kcal} / \mathrm{kg} /$ day but not more than 25 to $30 \mathrm{kcal} / \mathrm{kg} /$ day, equivalent to 100 to $130 \%$ of the resting energy expenditure. Energy provision should be composed of 3 to $5 \mathrm{~g}$ (maximum $7 \mathrm{~g}$ ) per kilogram body weight carbohydrates and 0.8 to $1.0 \mathrm{~g}$ per kilogram body weight fat.

When continuous renal replacement therapy (CRRT) techniques are used it should be realized that they may result in additional losses of water-soluble, lowmolecular-weight substances, including nutrients [43]. Normalized protein catabolic rates of 1.4 to $1.8 \mathrm{~g} / \mathrm{kg} /$ day have been reported in patients with AKI receiving CRRT [44-46] and about $0.2 \mathrm{~g}$ amino acids are lost per liter of filtrate, amounting to a total daily loss of 10 to $15 \mathrm{~g}$ amino acids. In addition, 5 to $10 \mathrm{~g}$ protein are lost per day, depending on the type of therapy and dialyzer membrane. Similar amounts of protein and amino acids are typically lost by peritoneal dialysis. Nutritional support should account for these losses by providing a maximum of $1.7 \mathrm{~g}$ amino acids $/ \mathrm{kg} /$ day. Enteral feeding is associated with improved outcome/survival in ICU patients $[47,48]$ and should be recommended for patients with AKI.

In children with AKI, physiological macronutrient requirements are age dependent, reflecting the developmental dynamics of growth and metabolism. Although these recommendations are limited to observational studies, it is generally agreed that critically ill children, like adults, should receive 100 to $130 \%$ of the basal energy expenditure, which can be estimated with acceptable precision and accuracy by the Caldwell-Kennedy equation [49]:

Resting energy expenditure $(\mathrm{kcal} / \mathrm{kg} /$ day $)=$

$22+31.05 \times$ weight $(\mathrm{kg})+1.16 \times$ age (years)

In a recent survey of the nutritional management of 195 children with AKI on CRRT, the maximal calorie prescription in the course of treatment averaged 53, 31, and $21 \mathrm{kcal} / \mathrm{kg} / \mathrm{day}$, and that for protein intake 2.4, 1.9, and $1.3 \mathrm{~g} / \mathrm{kg} /$ day in children aged $<1$ year, 1 to 13 years, and $>13$ years, respectively [50]. Although not validated by outcome studies, these figures provide an orientation for the macronutrient supply typically achieved in and tolerated by children with AKI receiving CRRT.

D4: In critically ill patients, we suggest insulin therapy targeting plasma glucose 110 to $149 \mathrm{mg} / \mathrm{dl}$ (6.1 to $8.3 \mathrm{mmol} / \mathrm{l})$ (Grade 2C).
D5: We suggest achieving a total energy intake of 20 to $30 \mathrm{kcal} / \mathrm{kg} /$ day in patients with any stage of AKI (Grade 2C).

D6: We suggest avoiding restriction of protein intake with the aim of preventing or delaying initiation of RRT (Grade 2D).

D7: We suggest administering 0.8 to $1.0 \mathrm{~g} / \mathrm{kg} / \mathrm{day}$ protein in noncatabolic AKI patients without need for dialysis (Grade 2D), 1.0 to $1.5 \mathrm{~g} / \mathrm{kg} /$ day in patients with AKI on RRT (Grade 2D), and up to a maximum of $1.7 \mathrm{~g} / \mathrm{kg} /$ day in patients on CRRT and in hypercatabolic patients (Grade 2D).

D8: We suggest providing nutrition preferentially via the enteral route in patients with AKI (Grade 2C).

\section{Diuretics}

On the basis of various mechanistic studies and support from preclinical data [51-54], loop diuretics (especially furosemide) have long been prescribed in the acute-care setting [55-57], and a number of RCTs have tested whether furosemide is beneficial for prevention or treatment of AKI. Specifically, prophylactic furosemide was found to be ineffective or harmful when used to prevent AKI after cardiac surgery [52,53], and to increase the risk of AKI when given to prevent contrast-induced AKI [54]. Epidemiologic data suggest that the use of loop diuretics may increase mortality in patients with critical illness and AKI [58], along with conflicting data that suggest no harm in AKI [59]. Finally, furosemide therapy was also ineffective and possibly harmful when used to treat AKI $[51,60]$. A systematic review and meta-analysis by $\mathrm{Ho}$ and Power also included six studies that used furosemide to treat AKI, with doses ranging from 600 to 3,400 mg/day [61]. No significant reduction was found for in-hospital mortality or for RRT requirement. Furosemide may be useful in achieving fluid balance to facilitate mechanical ventilation according to the lung-protective ventilation strategy in hemodynamically stable patients with acute lung injury. However, a beneficial role for loop diuretics in facilitating discontinuation of RRT in AKI is not evident from clinical studies $[62,63]$.

The often retrospective and/or underpowered studies using prophylactic mannitol did not meet the criteria of the Work Group to be included in formulation of recommendations. Mannitol is often added to the priming fluid of the cardiopulmonary bypass system to reduce the incidence of renal dysfunction, but the results of these studies are not very convincing [64]. Two small randomized trials - one in patients with pre-existing normal renal function [65], the second in patients with established renal dysfunction [66] - did not find differences for any measured variable of renal function. More 
convincing are the results obtained with the preventive administration of mannitol, just before clamp release, during renal transplantation $[67,68]$. The sparse controlled data available have shown that $250 \mathrm{ml}$ of $20 \%$ mannitol given immediately before vessel clamp removal reduces the incidence of post-transplant AKI, as indicated by a lower requirement of post-transplant dialysis. However, 3 months after transplantation, no difference is found in kidney function compared with patients who did not receive mannitol [69]. Finally, it has been suggested that mannitol is beneficial in rhabdomyolysis by stimulating osmotic diuresis and by lowering the intracompartmental pressure in the affected crushed limbs [70-72]; again, these studies were either not randomized or were underpowered. A separate guideline on crush injury associated with disasters, mainly earthquake victims, has now been published by the International Society of Nephrology Renal Disaster Relief Task Force [73].

D9: We recommend not using diuretics to prevent AKI (Grade 1B).

D10: We suggest not using diuretics to treat AKI, except in the management of volume overload (Grade 2C).

\section{Vasodilator therapy: dopamine, fenoldopam, and natriuretic peptides}

Three systematic reviews have reached identical conclusions that dopamine does not provide any benefit for prevention or early treatment of AKI [74-76]. There is also limited evidence that the use of dopamine to prevent or treat AKI causes harm. Dopamine can trigger tachyarrhythmias and myocardial ischemia, decrease intestinal blood flow, cause hypopituitarism, and suppress T-cell function [77]. Fenoldopam mesylate is a pure dopamine type-1 receptor agonist that has similar hemodynamic renal effects as low-dose dopamine, without systemic $\alpha$ adrenergic or $\beta$-adrenergic stimulation [78]. A metaanalysis found that fenoldopam reduces the need for RRT and in-hospital death in cardiovascular surgery patients [79]. However, the pooled studies included both prophylactic and early therapeutic studies, as well as propensityadjusted case-matched studies (rather than purely randomized trials). A 1,000-patient RCT of fenoldopam to prevent the need for RRT after cardiac surgery is currently underway (ClinicalTrials.gov: NCT00621790); meanwhile, this remains an unproven indication for fenoldopam therapy.

Our analysis of existing data from suitable prophylactic studies of adequate size and study design that reported AKI incidence in patients randomized to fenoldopam versus placebo revealed a pooled relative risk (RR) of 0.96 ( $95 \% \mathrm{CI}=0.76$ to $1.2 ; P=$ not significant). Only one study reported mortality (8-day) in sepsis patients randomized to fenoldopam (35\%, $n=150)$ versus placebo $(44 \%$, $n=150)$, with a RR of $0.79(95 \% \mathrm{CI}=0.59$ to $1.05 ; P=0.1)$ [80]. As therapy for AKI, only one study reported (21-day) mortality in critically ill patients with early AKI randomized to fenoldopam $(11 / 80,13.8 \%)$ versus placebo ( $n=19 / 75,25.3 \% ; P=0.068)$ [81]. Another study reported the change in renal function in AKI patients randomized to fenoldopam $(n=50)$ versus dopamine $(n=50)$, defined by the absolute $\mathrm{SCr}$ change between the beginning and end of the study drug infusion and the maximum decrease from study entry, which were significantly larger in the fenoldopam group: $-0.53 \pm 0.47$ vs. dopamine: $-0.34 \pm 0.38 \mathrm{md} / \mathrm{dl}, P=0.027$ [82]. Overall, therefore, no data from adequately powered multicenter trials with clinically significant end-points and adequate safety are available to recommend fenoldopam to either prevent or treat AKI. The guideline recommendation against using fenoldopam places a high value on avoiding potential hypotension and harm associated with the use of this vasodilator in high-risk perioperative and ICU patients, and a low value on potential benefit, which is currently only suggested by relatively low-quality single-center trials.

Nigwekar and colleagues recently conducted a systematic review and meta-analysis of ANP for management of AKI [83]. They found 19 relevant studies, among which 11 studies were for prevention and eight were for treatment of AKI. Pooled analysis of the eight treatment studies, involving 1,043 participants, did not show significant difference for either RRT requirement or mortality between the ANP and control groups. However, low-dose ANP preparations were associated with significant reduction in RRT requirement $(\mathrm{OR}=0.34 ; 95 \% \mathrm{CI}=$ 0.12 to $0.96 ; P=0.04$ ). The incidence of hypotension was not different between the ANP and control groups for low-dose studies, whereas it was significantly higher in the ANP group in the high-dose ANP studies $(\mathrm{OR}=4.13$; 95\% CI $=1.38$ to $12.41 ; P<0.01)$. Finally, a pooled analysis of studies that examined oliguric AKI did not show any significant benefit from ANP for RRT requirement or mortality. Only two of the treatment studies included in Nigwekar and colleagues' analysis $[84,85]$ were of adequate size and quality to meet the criteria for our systematic review, which found no significant inconsistencies in the findings of both trials that (combined) included 720 subjects ( 351 treated with ANP). Therefore, although subset analyses separating low-dose from highdose ANP trials suggest potential benefits, the preponderance of the literature suggests no benefit of ANP therapy for AKI. The Work Group therefore suggests this agent not to be used to prevent or treat AKI.

Nesiritide (b-type natriuretic peptide) is the latest natriuretic peptide introduced for clinical use, and is approved by the US Food and Drug Administration only 
for the therapy of acute, decompensated congestive heart failure. Meta-analysis of outcome data from these and some other nesiritide congestive heart failure trials has generated some controversy [86-88]. Sackner-Bernstein and colleagues analyzed mortality data from 12 randomized trials; three trials provided 30-day mortality data, and found a trend towards an increased risk of death in nesiritide-treated subjects [86]. In another meta-analysis of five randomized trials that included 1,269 subjects [87], the same investigators found that there was a relationship between nesiritide use and worsening renal function, defined as SCr increase $>0.5 \mathrm{mg} / \mathrm{dl}(>44.2 \mu \mathrm{mol} /$ 1). Nesiritide doses $\leq 0.03 \mu \mathrm{g} / \mathrm{kg} /$ minute and even at doses $\leq 0.015 \mu \mathrm{g} / \mathrm{kg} /$ minute significantly increased the risk of renal dysfunction compared with non-inotrope-based controls or compared with all control groups (including inotropes). There was no difference in dialysis rates between the groups. Another retrospective study determined independent risk factors for 60-day mortality by multivariate analysis in a cohort of 682 older heart-failure patients treated with nesiritide versus those who were not [89]. When patients were stratified according to nesiritide usage, AKI emerged as an independent risk factor for mortality only among patients who received the drug. Strikingly, among these heart-failure patients who developed AKI, nesiritide usage emerged as the only independent predictor of mortality. A 7,000-patient multicenter RCT in acute decompensated heart failure has recently assessed the clinical effectiveness of nesiritide therapy for acute decompensated heart failure (the Acute Study of Clinical Effectiveness of Nesiritide in Decompensated Heart Failure; Clinicaltrials.gov: NCT00475852).

A prospective, randomized clinical trial (the Nesiritide Study) found no benefit of nesiritide for 21-day dialysis and/or death in patients undergoing high-risk cardiovascular surgery [90]. However, this study did demonstrate that the prophylactic use of nesiritide was associated with reduced incidence of AKI in the immediate postoperative period (nesiritide $6.6 \%$ vs. placebo $28.5 \%$; $P=0.004)$. Recently, Lingegowda and colleagues investigated whether the observed renal benefits of nesiritide had any long-term impact on cumulative patient survival and renal outcomes [91]. Data on all 94 patients from the Nesiritide Study were obtained with a mean follow-up period of $20.8 \pm 10.4$ months. No differences in cumulative survival between the groups were noted, but patients with in-hospital incidence of AKI had a higher rate of mortality than those with no AKI (41.4\% vs. $10.7 \%$; $P=0.002$ ). The possible renoprotection provided by nesiritide in the immediate postoperative period was not associated with improved long-term survival in patients undergoing high-risk cardiovascular surgery.

Although evidence from a variety of small studies suggests the potential for therapy with natriuretic peptides to be useful for the prevention or treatment of AKI in a variety of settings, there are no definitive trials to support the use of atrial natriuretic peptide (ANP), btype natriuretic peptide, or nesiritide for these purposes. The Work Group therefore suggests these agents should not be used for prevention or treatment of AKI.

D11: We recommend not using low-dose dopamine to prevent or treat AKI (Grade 1A).

D12: We suggest not using fenoldopam to prevent or treat AKI (Grade 2C).

D13: We suggest not using ANP to prevent (Grade 2C) or treat (Grade 2B) AKI.

\section{Other pharmacologic therapies}

AKI occurs in $60 \%$ of neonates suffering from perinatal asphyxia [92], and experimental studies have indicated an important role for adenosine-mediated vasoconstriction in neonatal kidneys exposed to normocapnic hypoxemia [93]. A potential renoprotective effect of theophylline in perinatal asphyxia has been assessed in three randomized, placebo-controlled clinical trials [94-96], including a total of 171 term neonates. Theophylline was uniformly administered in the first hour of life as a single intravenous bolus at a dose of $5 \mathrm{mg} / \mathrm{kg}[94,96]$ or $8 \mathrm{mg} / \mathrm{kg}$ [95]. All three studies observed significantly higher glomerular filtration rate, higher urine output with more negative fluid balance, and lower urinary $\beta_{2}$-microglobulin excretion with theophylline as compared with placebo during the first 3 to 5 days of life. In each study, theophylline treatment was associated with a significantly reduced risk of severe renal dysfunction (17 to $25 \%$ vs. 55 to $60 \%$ in the placebo group; $R R=0.3$ to 0.41 ). The beneficial effect was selective for kidney function, whereas the incidence of extra-renal complications was unaltered. Patient survival was not affected by treatment. In line with these studies in mature neonates, a similar improvement of glomerular filtration rate and urine output was observed during the first 2 days of life by administration of $1 \mathrm{mg} / \mathrm{kg}$ theophylline versus placebo in 50 very preterm neonates with respiratory distress syndrome [97]. Follow-up of renal function throughout the first year of life by Bhat and colleagues found equally normal glomerular and tubular function in both groups from 6 weeks of age onward [95]. Hence, while theophylline clearly improves renal function in the first week of life in postasphyctic neonates, the overall benefit from this intervention in neonatal intensive care is less evident in view of the complete long-term recovery of renal function in the placebo-treated controls and the absence of an effect on patient survival.

By contrast, adenosine antagonism does not appear beneficial in cardiorenal syndrome. Three pivotal phase III trials in a total of 2,500 patients were recently completed, aiming to corroborate the renoprotective 
effects of rolofylline in patients with cardiorenal syndrome, and to establish drug safety. The final results of the PROTECT trial have recently been published [98]. Rolofylline, as compared with placebo, did not provide a benefit with respect to the three primary end-points: survival, heart-failure status, and changes in renal function. Persistent renal impairment developed in 15.0\% of patients in the rolofylline group and in $13.7 \%$ of patients in the placebo group $(P=0.44)$. By 60 days, death or readmission for cardiovascular or renal causes had occurred in similar proportions of both groups of patients. Adverse-event rates were similar overall; however, only patients in the rolofylline group had seizures, a known potential adverse effect of $\mathrm{A}_{1}$-receptor antagonists. Rolofylline therefore does not appear to be effective for treatment of cardiorenal AKI.

Based on an analysis of the three RCTs with insulin-like growth factor-1 that are currently available [99-101] and which were overall negative or at least equivocal, the Work Group recommends against its use in patients with AKI.

D14: We recommend not using recombinant human insulin-like growth factor-1 to prevent or treat AKI (Grade 1B).

D15: We suggest that a single dose of theophylline may be given in neonates with severe perinatal asphyxia, who are at high risk of AKI (Grade 2B).

\section{Avoiding nephrotoxins}

Aminoglycosides exhibit a number of favorable pharmacokinetic and pharmacodynamic advantages, but a major dose-limiting toxicity of the aminoglycosides remains the risk of drug-induced AKI [102]. The risk of AKI attributable to aminoglycosides is sufficiently high (up to $25 \%$ in some series, depending upon the definition of AKI used and the population studied) [103-109] that they should no longer be used for standard empirical or directed treatment, unless no other suitable alternatives exist.

When still required, the potential efficacy of singledose daily regimens (or other extended dosing treatment programs) of aminoglycosides versus multiple-daily dosing strategies has been extensively studied in numerous controlled and uncontrolled clinical studies over many years [110-121], and the subject has been the focus of a number of formal meta-analyses [122-127]. The cumulative results of this evidence-based review and numerous meta-analyses indicate that once-daily dosing strategies generally result in less AKI when compared with multiple-dose dosing strategies, although the benefit accrued by the single-daily dose strategy is modest and inconsistent across a number of these studies.

In view of the high variability of the pharmacokinetic characteristics of aminoglycosides, therapeutic drug monitoring in combination with or independent from single-dose daily treatment regimens is recommended. In single-dose or extended-dose treatment strategies, the peak drug level should be at least 10 -fold greater than the minimum inhibitory concentration of the infecting microorganism. The trough level should be undetectable by 18 to 24 hours to limit accumulation of aminoglycosides in renal tubular cells and to minimize the risk of AKI.

Aminoglycoside aerosol delivery systems are now in use to provide high intrapulmonary antibiotic levels with minimal systemic and kidney concentrations of the antibiotic. However, significant nephrotoxicity with the use of inhaled tobramycin has been described in at least two cases $[128,129]$.

The safety and efficacy of lipid formulations of amphotericin B have been studied in numerous experimental and clinical trials with conventional amphotericin $\mathrm{B}$ as the comparator [130-142]. A detailed analysis of these various trials, and a number of meta-analyses that have analyzed this clinical question, concluded that the lipid formulations are less nephrotoxic than amphotericin B deoxycholate [133,135]. When feasible, we recommend that lipid formulations supplant the use of conventional amphotericin B to reduce the risk of nephrotoxicity. Alternatively, when feasible, it may be best to avoid polyene antifungal agents entirely and use alternative agents, such as the azoles and echinocandins [143-147].

D16: We suggest not using aminoglycosides for the treatment of infections unless no suitable, less nephrotoxic, therapeutic alternatives are available (Grade $2 \mathrm{~A}$ ).

D17: We suggest that, in patients with normal kidney function in steady state, aminoglycosides are administered as a single dose daily rather than multiple-dose daily treatment regimens (Grade 2B).

D18: We recommend monitoring aminoglycoside drug levels when treatment with multiple daily dosing is used for more than 24 hours (Grade 1A).

D19: We suggest monitoring aminoglycoside drug levels when treatment with single-daily dosing is used for more than 48 hours (Grade 2C).

D20: We suggest using topical or local applications of aminoglycosides (for example, respiratory aerosols, instilled antibiotic beads), rather than intravenous application, when feasible and suitable (Grade 2B).

D21: We suggest using lipid formulations of amphotericin $B$ rather than conventional formulations of amphotericin B (Grade 2A).

D22: In the treatment of systemic mycoses or parasitic infections, we recommend using azole 
antifungal agents and/or the echinocandins rather than conventional amphotericin $B$, if equal therapeutic efficacy can be assumed (Grade 1A).

\section{Surgical patients}

A comprehensive meta-analysis examining off-pump versus conventional coronary artery bypass surgery found that the off-pump technique was associated with a statistically significant $40 \%$ lower odds of postoperative AKI and a nonsignificant 33\% lower odds for dialysis requirement [148]. Within the selected trials, off-pump coronary artery bypass graft surgery was not associated with a significant decrease in mortality. It is apparent from this meta-analysis that the trials were clinically heterogeneous, particularly with regard to their definitions of kidney outcomes, and mostly were of poor to fair quality (based on the Jadad score). The very low event rates (often zero or one patient) make the estimates suspect and highly imprecise. There is also a question of publication bias. There are several large trials in progress that are likely to generate more definitive data. The Work Group concluded that there was not enough evidence at present to recommend off-pump coronary artery bypass for reducing AKI or the need for RRT.

A meta-analysis did not find evidence that $N$-acetylcysteine used perioperatively could alter mortality or renal outcomes after major cardiovascular or abdominal cancer surgery when radiocontrast agents are not used [149]. Only a single study has compared $N$-acetylcysteine with placebo in critically ill patients with hypotension and was also negative [150].

D23: We suggest that off-pump coronary artery bypass graft surgery not be selected solely for the purpose of reducing perioperative AKI or need for RRT (Grade 2C).

D24: We suggest not using $\mathrm{N}$-acetylcysteine to prevent AKI in critically ill patients with hypotension (Grade 2D).

D25: We recommend not using oral or intravenous $\mathrm{N}$-acetylcysteine for prevention of postsurgical AKI (Grade 1A).

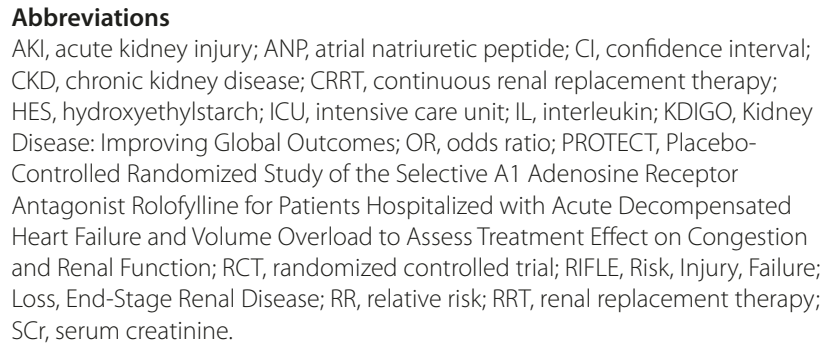

AKI, acute kidney injury; ANP, atrial natriuretic peptide; Cl, confidence interval; CKD, chronic kidney disease; CRRT, continuous renal replacement therapy; HES, hydroxyethylstarch; ICU, intensive care unit; IL, interleukin; KDIGO, Kidney Disease: Improving Global Outcomes; OR, odds ratio; PROTECT, PlaceboControlled Randomized Study of the Selective A1 Adenosine Receptor Antagonist Rolofylline for Patients Hospitalized with Acute Decompensated Heart Failure and Volume Overload to Assess Treatment Effect on Congestion and Renal Function; RCT, randomized controlled trial; RIFLE, Risk, Injury, Failure; Loss, End-Stage Renal Disease; RR, relative risk; RRT, renal replacement therapy; $\mathrm{SCr}$, serum creatinine.

Competing interests

JAK has served as an Advisor/Consultant for Abbott, Alere, Astute Medical, Baxter, CytoSorbents, EBI, Eli Lilly, Fresenius, Gambro, Siemens and Spectral
Diagnostics, and as a Speaker for Baxter, Fresenius, and Gambro. He has also received grant/research support from Astute Medical, Baxter, CytoSorbents and Gambro. NL declares that he has no competing interests.

\section{Authors' information}

JAK is Professor of Critical Care Medicine, Medicine, Bioengineering and Clinical and Translational Science, and Vice Chair for Research within the Department of Critical Care Medicine at the University of Pittsburgh. He is also the Director of the Program on Bioengineering and Organ Support for the Clinical Research Investigation and Systems Modeling of Acute Illness Center at the University of Pittsburgh. NL is Emeritus Professor of Medicine and former Chief of the Renal Division at the University Hospital of Ghent.

\section{Acknowledgements}

A special debt of gratitude is owed to the KDIGO Co-Chairs Kai-Uwe Eckardt and Bertram Kasiske and the KDIGO Board for their invaluable guidance throughout the development of this guideline. In particular, the authors thank the Evidence Review Team members - Katrin Uhlig, Jose Calvo-Broce, Aneet Deo, and Amy Earley - for their substantial contribution to the rigorous assessment of the available evidence. They are also especially grateful to the Work Group members for their expertise throughout the entire process of literature review, data extraction, meeting participation, the critical writing and editing of the statements and rationale, which made the publication of this guideline possible. The generous gift of their time and dedication is greatly appreciated. Finally, and on behalf of the Work Group, the authors gratefully acknowledge the careful assessment of the draft guideline by external reviewers. The Work Group considered all of the valuable comments made, and where appropriate, suggested changes were incorporated into the final publication.

\section{Author details}

'The Crisma Center, Department of Critical Care Medicine, 604 Scaife Hall, University of Pittsburgh School of Medicine, Pittsburgh, PA 15261, USA. ${ }^{2}$ Ghent University Hospital, De Pintelaan 185, Ghent B9000, Belgium. ${ }^{3} \mathrm{KDIGO}$ AKI Guideline Work Group: John A Kellum (Work Group Co-Chair), University of Pittsburgh, PA, USA; Norbert Lameire (Work Group Co-Chair), University of Ghent, Belgium; Peter Aspelin, Karolinska Institute, Sweden; Rashad S Barsoum, Cairo University, Egypt; Emmanuel A Burdmann, University of São Paulo, Brazil; Stuart L Goldstein, Cincinnati Children's Hospital Medical Center, OH, USA; Charles A Herzog, Hennepin County Medical Center, MN, USA; Michael Joannidis, Medical University Innsbruck, Austria; Andreas Kribben, University of Duisburg-Essen, Germany; Andrew S Levey, Tufts University, MA, USA Alison M Macleod, University of Aberdeen, UK; Ravindra L Mehta, University of California, San Diego, CA, USA; Patrick T Murray, University College Dublin Ireland; Saraladevi Naicker, University of the Witwatersrand, South Africa; Steven M Opal, Brown University, RI, USA; Franz Schaefer, Heidelberg University Hospital, Germany; Miet Schetz, University of Leuven, Belgium; and Shigehiko Uchino, Jikei University School of Medicine, Japan.

\section{Published: 4 February 2013}

\section{References}

1. KDIGO AKI Work Group: KDIGO clinical practice guideline for acute kidney injury. Kidney Int Supp/ 2012, 2:1-138.

2. Kidney Disease: Improving Global Outcomes [www.kdigo.org]

3. KDIGO Clinical Practice Guidelines: Online Appendix F [http://www.kdigo.org/clinical_practice_guidelines/AKI.php]

4. Uhlig K, Macleod A, Craig J, Lau J, Levey AS, Levin A, Moist L, Steinberg E, Walker R, Wanner C, Lameire N, Eknoyan G: Grading evidence and recommendations for clinical practice guidelines in nephrology. $\mathrm{A}$ position statement from Kidney Disease: Improving Global Outcomes (KDIGO). Kidney Int 2006, 70:2058-2065.

5. Atkins D, Best D, Briss PA, Eccles M, Falck-Ytter Y, Flottorp S, Guyatt GH, Harbour RT, Haugh MC, Henry D, Hill S, Jaeschke R, Leng G, Liberati A, Magrini N, Mason J, Middleton P, Mrukowicz J, O'Connell D, Oxman AD, Phillips B, Schünemann HJ, Edejer TT, Varonen H, Vist GE, Williams JW Jr, Zaza S; GRADE Working Group: Grading quality of evidence and strength of recommendations. BMJ 2004, 328:1490.

6. Hoste EA, Clermont G, Kersten A, Venkataraman R, Angus DC, De Bacquer D, Kellum JA: RIFLE criteria for acute kidney injury are associated with hospital mortality in critically ill patients: a cohort analysis. Crit Care 2006, 10:R73. 
7. Uchino S, Bellomo R, Goldsmith D, Bates S, Ronco C: An assessment of the RIFLE criteria for acute renal failure in hospitalized patients. Crit Care Med 2006, 34:1913-1917.

8. Bellomo R, Ronco C, Kellum JA, Mehta RL, Palevsky P: Acute renal failure - definition, outcome measures, animal models, fluid therapy and information technology needs: the Second International Consensus Conference of the Acute Dialysis Quality Initiative (ADQI) Group. Crit Care 2004, 8:R204-R212.

9. Bagshaw SM, George C, Dinu I, Bellomo R: A multi-centre evaluation of the RIFLE criteria for early acute kidney injury in critically ill patients. Nephrol Dial Transplant 2008, 23:1203-1210.

10. Kellum JA, Bellomo R, Ronco C: Classification of acute kidney injury using RIFLE: what's the purpose? Crit Care Med 2007, 35:1983-1984.

11. Ricci Z, Cruz D, Ronco C: The RIFLE criteria and mortality in acute kidney injury: a systematic review. Kidney Int 2008, 73:538-546.

12. Thakar CV, Christianson A, Freyberg R, Almenoff P, Render ML: Incidence and outcomes of acute kidney injury in intensive care units: a Veterans Administration study. Crit Care Med 2009, 37:2552-2558.

13. Joannidis M, Metnitz B, Bauer P, Schusterschitz N, Moreno R, Druml W, Metnitz PG: Acute kidney injury in critically ill patients classified by AKIN versus RIFLE using the SAPS 3 database. Intensive Care Med 2009, 35:1692-1702.

14. Ostermann M, Chang RW: Acute kidney injury in the intensive care unit according to RIFLE. Crit Care Med 2007, 35:1837-1843.

15. Mehta RL, Kellum JA, Shah SV, Molitoris BA, Ronco C, Warnock DG, Levin A: Acute Kidney Injury Network: report of an initiative to improve outcomes in acute kidney injury. Crit Care 2007, 11:R31.

16. Akcan-Arikan A, Zappitelli M, Loftis LL, Washburn KK, Jefferson LS, Goldstein SL: Modified RIFLE criteria in critically ill children with acute kidney injury. Kidney Int 2007, 71:1028-1035.

17. Hoste EA, Kellum JA: Acute renal failure in the critically ill: impact on morbidity and mortality. Contrib Nephrol 2004, 144:1-11.

18. Hackworth LA, Wen X, Clermont G, Kellum JA: Hospital versus communityacquired acute kidney injury in the critically ill: differences in epidemiology [abstract]. J Am Soc Nephrol 2009, 20:115A

19. Stewart J, Findlay G, Smith N, Kelly K, Mason M: Adding Insult to Injury: A Review of the Care of Patients who died in Hospital with a Primary Diagnosis of Acute Kidney Injury (Acute Renal Failure). London: National Confidential Enquiry into Patient Outcome and Death; 2009:1-98.

20. Hall IE, Coca SG, Perazella MA, Eko UU, Luciano RL, Peter PR, Han WK, Parikh CR: Risk of poor outcomes with novel and traditional biomarkers at clinical AKI diagnosis. Clin J Am Soc Nephrol 2011, 6:2740-2749.

21. Ali T, Khan I, Simpson W, Prescott G, Townend J, Smith W, Macleod A: Incidence and outcomes in acute kidney injury: a comprehensive population-based study. J Am Soc Nephrol 2007, 18:1292-1298.

22. Bouchard J, Soroko SB, Chertow GM, Himmelfarb J, I kizler TA, Paganini EP, Mehta RL: Fluid accumulation, survival and recovery of kidney function in critically ill patients with acute kidney injury. Kidney Int 2009, 76:422-427.

23. Payen D, de Pont AC, Sakr Y, Spies C, Reinhart K, Vincent JL: A positive fluid balance is associated with a worse outcome in patients with acute renal failure. Crit Care 2008, 12:R74

24. Prowle JR, Bellomo R: Continuous renal replacement therapy: recent advances and future research. Nat Rev Nephrol 2010, 6:521-529.

25. Finfer S, Bellomo R, Boyce N, French J, Myburgh J, Norton R: A comparison of albumin and saline for fluid resuscitation in the intensive care unit. $N$ Eng/J Med 2004, 350:2247-2256.

26. Perel P, Roberts I, Pearson M: Colloids versus crystalloids for fluid resuscitation in critically ill patients. Cochrane Database Syst Rev 2007, 4:CD000567.

27. Wiedermann CJ, Dunzendorfer S, Gaioni LU, Zaraca F, Joannidis M: Hyperoncotic colloids and acute kidney injury: a meta-analysis of randomized trials. Crit Care 2010, 14:R191.

28. Prowle JR, Bellomo R: Fluid administration and the kidney. Curr Opin Crit Care 2010, 16:332-336

29. Kaplan LJ, Kellum JA: Fluids, pH, ions and electrolytes. Curr Opin Crit Care 2010, 16:323-331.

30. De Backer D, Biston P, Devriendt J, Madl C, Chochrad D, Aldecoa C, Brasseur A, Defrance P, Gottignies P, Vincent $\mathrm{J}$ : Comparison of dopamine and norepinephrine in the treatment of shock. N Engl J Med 2010, 362:779-789.

31. Delmas A, Leone M, Rousseau S, Albanese J, Martin C: Clinical review: Vasopressin and terlipressin in septic shock patients. Crit Care 2005, 9:212-222.
32. Russell JA, Walley KR, Singer J, Gordon AC, Hébert PC, Cooper DJ, Holmes CL, Mehta S, Granton JT, Storms MM, Cook DJ, Presneill JJ, Ayers D; VASST Investigators: Vasopressin versus norepinephrine infusion in patients with septic shock. N Engl J Med 2008, 358:877-887.

33. Gordon AC, Russell JA, Walley KR, Singer J, Ayers D, Storms MM, Holmes CL, Hébert PC, Cooper DJ, Mehta S, Granton JT, Cook DJ, Presneill JJ: The effects of vasopressin on acute kidney injury in septic shock. Intensive Care Med 2010, 36:83-91

34. Brienza N, Giglio MT, Marucci M, Fiore T: Does perioperative hemodynamic optimization protect renal function in surgical patients? A meta-analytic study. Crit Care Med 2009, 37:2079-2090.

35. Wiener RS, Wiener DC, Larson RJ: Benefits and risks of tight glucose control in critically ill adults: a meta-analysis. JAMA 2008, 300:933-944.

36. Griesdale DE, de Souza RJ, van Dam RM, Heyland DK, Cook DJ, Malhotra A, Dhaliwal R, Henderson WR, Chittock DR, Finfer S, Talmor D: Intensive insulin therapy and mortality among critically ill patients: a meta-analysis including NICE-SUGAR study data. CMAJ 2009, 180:821-827.

37. NICE-SUGAR Study Investigators, Finfer $S$, Chittock DR, Su SY, Blair D, Foster D, Dhingra V, Bellomo R, Cook D, Dodek P, Henderson WR, Hébert PC, Heritier S, Heyland DK, McArthur C, McDonald E, Mitchell I, Myburgh JA, Norton R, Potter J, Robinson BG, Ronco JJ: Intensive versus conventional glucose control in critically ill patients. N Engl J Med 2009, 360:1283-1297.

38. Btaiche IF, Mohammad RA, Alaniz C, Mueller BA: Amino acid requirements in critically ill patients with acute kidney injury treated with continuous renal replacement therapy. Pharmacotherapy 2008, 28:600-613.

39. Cano N, Fiaccadori E, Tesinsky P, Toigo G, Druml W, Kuhlmann M, Mann H, Horl WH: ESPEN guidelines on enteral nutrition: adult renal failure. Clin Nutr 2006, 25:295-310.

40. Druml W: Nutritional management of acute renal failure. J Ren Nutr 2005, 15:63-70.

41. McClave SA, Hurt RT: Clinical guidelines and nutrition therapy: better understanding and greater application to patient care. Crit Care Clin 2010, 26:451-466.

42. McClave SA, Martindale RG, Vanek VW, McCarthy M, Roberts P, Taylor B, Ochoa JB, Napolitano L, Cresci G: Guidelines for the provision and assessment of nutrition support therapy in the adult critically ill patient: Society of Critical Care Medicine (SCCM) and American Society for Parenteral and Enteral Nutrition (A.S.P.E.N.). JPEN J Parenter Enteral Nutr 2009, 33:277-316.

43. Druml W: Metabolic aspects of continuous renal replacement therapies. Kidney Int Supp/ 1999, 72:S56-S61.

44. Chima CS, Meyer L, Hummell AC, Bosworth C, Heyka R, Paganini EP, Werynski A: Protein catabolic rate in patients with acute renal failure on continuous arteriovenous hemofiltration and total parenteral nutrition. J Am SOC Nephrol 1993, 3:1516-1521.

45. Leblanc M, Garred L, Cardinal J, Pichette V, Nolin L, Ouimet D, Geadah D: Catabolism in critical illness: estimation from urea nitrogen appearance and creatinine production during continuous renal replacement therapy. Am J Kidney Dis 1998, 32:444-453.

46. Marshall MR, GolperTA, Shaver MJ, Alam MG, Chatoth DK: Urea kinetics during sustained low-efficiency dialysis in critically ill patients requiring renal replacement therapy. Am J Kidney Dis 2002, 39:556-570.

47. Metnitz PG, Krenn CG, Steltzer H, Lang T, Ploder J, Lenz K, Le Gall JR, Druml W: Effect of acute renal failure requiring renal replacement therapy on outcome in critically ill patients. Crit Care Med 2002, 30:2051-2058.

48. Scheinkestel CD, Kar L, Marshall K, Bailey M, Davies A, Nyulasi I, Tuxen DV Prospective randomized trial to assess caloric and protein needs of critically III, anuric, ventilated patients requiring continuous renal replacement therapy. Nutrition 2003, 19:909-916.

49. Caldwell MD, Kennedy-Caldwell C: Normal nutritional requirements. Surg Clin North Am 1981, 61:489-507.

50. Zappitelli M, Goldstein SL, Symons JM, Somers MJ, Baum MA, Brophy PD, Blowey D, Fortenberry JD, Chua AN, Flores FX, Benfield MR, Alexander SR, Askenazi D, Hackbarth R, Bunchman TE; Prospective Pediatric Continuous Renal Replacement Therapy Registry Group: Protein and calorie prescription for children and young adults receiving continuous renal replacement therapy: a report from the Prospective Pediatric Continuous Renal Replacement Therapy Registry Group. Crit Care Med 2008, 36:3239-3245.

51. Cantarovich F, Rangoonwala B, Lorenz H, Verho M, Esnault VL: High-dose furosemide for established ARF: a prospective, randomized, double-blind, placebo-controlled, multicenter trial. Am J Kidney Dis 2004, 44:402-409.

52. Lassnigg A, Donner E, Grubhofer G, Presterl E, Druml W, Hiesmayr M: Lack of 
renoprotective effects of dopamine and furosemide during cardiac surgery. J Am Soc Nephrol 2000, 11:97-104.

53. Lombardi R, Ferreiro A, Servetto $C$ : Renal function after cardiac surgery: adverse effect of furosemide. Ren Fail 2003, 25:775-786

54. Solomon R, Werner C, Mann D, D'Elia J, Silva P: Effects of saline, mannitol, and furosemide to prevent acute decreases in renal function induced by radiocontrast agents. N Engl J Med 1994, 331:1416-1420.

55. Karajala V, Mansour W, Kellum JA: Diuretics in acute kidney injury. Minerva Anestesiol 2009, 75:251-257.

56. Ponto LL, Schoenwald RD: Furosemide (frusemide). A pharmacokinetic/ pharmacodynamic review (Part II). Clin Pharmacokinet 1990, 18:460-471

57. Ponto LL, Schoenwald RD: Furosemide (frusemide). A pharmacokinetic/ pharmacodynamic review (Part I). Clin Pharmacokinet 1990, 18:381-408.

58. Mehta RL, Pascual MT, Soroko S, Chertow GM: Diuretics, mortality, and nonrecovery of renal function in acute renal failure. JAMA 2002, 288:2547-2553

59. Uchino S, Doig GS, Bellomo R, Morimatsu H, Morgera S, Schetz M, Tan I, Bouman C, Nacedo E, Gibney N, Tolwani A, Ronco C, Kellum JA; Beginning and Ending Supportive Therapy for the Kidney (B.E.S.T. Kidney) Investigators: Diuretics and mortality in acute renal failure. Crit Care Med 2004, 32:1669-1677

60. Ho KM, Sheridan DJ: Meta-analysis of frusemide to prevent or treat acute renal failure. BMJ 2006, 333:420.

61. Ho KM, Power BM: Benefits and risks of furosemide in acute kidney injury. Anaesthesia 2010, 65:283-293.

62. van der Voort PH, Boerma EC, Koopmans M, Zandberg M, de Ruiter J, Gerritsen RT, Egbers PH, Kingma WP, Kuiper MA: Furosemide does not improve renal recovery after hemofiltration for acute renal failure in critically ill patients: a double blind randomized controlled trial. Crit Care Med 2009, 37:533-538.

63. Uchino S, Bellomo R, Morimatsu H, Morgera S, Schetz M, Tan I, Bouman C, Macedo E, Gibney N, Tolwani A, Straaten HO, Ronco C, Kellum JA: Discontinuation of continuous renal replacement therapy: a post hoc analysis of a prospective multicenter observational study. Crit Care Med 2009, 37:2576-2582

64. Schetz M: Should we use diuretics in acute renal failure? Best Pract Res Clin Anaesthesiol 2004, 18:75-89.

65. Yallop KG, Sheppard SV, Smith DC: The effect of mannitol on renal function following cardio-pulmonary bypass in patients with normal pre-operative creatinine. Anaesthesia 2008, 63:576-582.

66. Smith MN, Best D, Sheppard SV, Smith DC: The effect of mannitol on renal function after cardiopulmonary bypass in patients with established renal dysfunction. Anaesthesia 2008, 63:701-704.

67. Schnuelle $P$, Johannes van der Woude F: Perioperative fluid management in renal transplantation: a narrative review of the literature. Transp/ Int 2006, 19:947-959.

68. van Valenberg PL, Hoitsma AJ, Tiggeler RG, Berden JH, van Lier HJ, Koene RA Mannitol as an indispensable constituent of an intraoperative hydration protocol for the prevention of acute renal failure after renal cadaveric transplantation. Transplantation 1987, 44:784-788.

69. Weimar W, Geerlings W, Bijnen AB, Obertop H, van Urk H, Lameijer LD, Wolff $E D$, Jeekel J: A controlled study on the effect of mannitol on immediate renal function after cadaver donor kidney transplantation. Transplantation 1983, 35:99-101.

70. Better OS, Rubinstein I, Winaver JM, Knochel JP: Mannitol therapy revisited (1940-1997). Kidney Int 1997, 52:886-894.

71. Sever MS, Vanholder R, Lameire N: Management of crush-related injuries after disasters. N Engl J Med 2006, 354:1052-1063.

72. Vanholder R, Sever MS, Erek E, Lameire N: Rhabdomyolysis. J Am Soc Nephrol $2000,11: 1553-1561$

73. Sever MS, Vanholder R: Recommendation for the management of crush victims in mass disasters. Nephrol Dial Transplant 2012, 27(Suppl 1):i1-i67.

74. Friedrich JO, Adhikari N, Herridge MS, Beyene J: Meta-analysis: low-dose dopamine increases urine output but does not prevent renal dysfunction or death. Ann Intern Med 2005, 142:510-524.

75. Kellum JA, J MD: Use of dopamine in acute renal failure: a meta-analysis. Crit Care Med 2001, 29:1526-1531.

76. Marik PE: Low-dose dopamine: a systematic review. Intensive Care Med 2002. 28:877-883.

77. Murray PT: Use of dopaminergic agents for renoprotection in the ICU. In Yearbook of Intensive Care and Emergency Medicine. Berlin: Springer-Verlag;
2003:637-648.

78. Murray PT: Fenoldopam: renal-dose dopamine redux? Crit Care Med 2006, 34:910-911.

79. Landoni G, Biondi-Zoccai GG, Marino G, Bove T, Fochi O, Maj G, Calabrò MG, Sheiban I, Tumlin JA, Ranucci M, Zangrillo A: Fenoldopam reduces the need for renal replacement therapy and in-hospital death in cardiovascular surgery: a meta-analysis. J Cardiothorac Vasc Anesth 2008, 22:27-33.

80. Morelli A, Ricci Z, Bellomo R, Ronco C, Rocco M, Conti G, De Gaetano A, Picchini U, Orecchioni A, Portieri M, Coluzzi F, Porzi P, Serio P, Bruno A, Pietropaoli P: Prophylactic fenoldopam for renal protection in sepsis: a randomized, double-blind, placebo-controlled pilot trial. Crit Care Med 2005, 33:2451-2456.

81. Tumlin JA, Finkel KW, Murray PT, Samuels J, Cotsonis G, Shaw AD: Fenoldopam mesylate in early acute tubular necrosis: a randomized, double-blind, placebo-controlled clinical trial. Am J Kidney Dis 2005, 46:26-34.

82. Brienza N, Malcangi V, Dalfino L, Trerotoli P, Guagliardi C, Bortone D, Faconda G, Ribezzi M, Ancona G, Bruno F, Fiore T: A comparison between fenoldopam and low-dose dopamine in early renal dysfunction of critically ill patients. Crit Care Med 2006, 34:707-714.

83. Nigwekar SU, Navaneethan SD, Parikh CR, Hix JK: Atrial natriuretic peptide for management of acute kidney injury: a systematic review and metaanalysis. Clin J Am Soc Nephrol 2009, 4:261-272.

84. Allgren RL, Marbury TC, Rahman SN, Weisberg LS, Fenves AZ, Lafayette RA, Sweet RM, Genter FC, Kurnik BR, Conger JD, Sayegh MH: Anaritide in acute tubular necrosis. Auriculin Anaritide Acute Renal Failure Study Group. N Eng/ J Med 1997, 336:828-834

85. Lewis J, Salem MM, Chertow GM, Weisberg LS, McGrew F, Marbury TC, Allgren RL: Atrial natriuretic factor in oliguric acute renal failure. Anaritide Acute Renal Failure Study Group. Am J Kidney Dis 2000, 36:767-774.

86. Sackner-Bernstein JD, Kowalski M, Fox M, Aaronson K: Short-term risk of death after treatment with nesiritide for decompensated heart failure: a pooled analysis of randomized controlled trials. JAMA 2005 293:1900-1905

87. Sackner-Bernstein JD, Skopicki HA, Aaronson KD: Risk of worsening renal function with nesiritide in patients with acutely decompensated heart failure. Circulation 2005, 111:1487-1491.

88. Topol EJ: Nesiritide - not verified. N Engl J Med 2005, 353:113-116.

89. Iglesias JI, DePalma L, Hom D, Antoniotti M, Ayoub S, Levine JS: Predictors of mortality in adult patients with congestive heart failure receiving nesiritide - retrospective analysis showing a potential adverse interaction between nesiritide and acute renal dysfunction. Nephrol Dial Transplant 2008, 23:144-153.

90. Ejaz AA, Martin TD, Johnson RJ, Winterstein AG, Klodell CT, Hess PJ Jr, Ali AK, Whidden EM, Staples NL, Alexander JA, House-Fancher MA, Beaver TM: Prophylactic nesiritide does not prevent dialysis or all-cause mortality in patients undergoing high-risk cardiac surgery. J Thorac Cardiovasc Surg 2009, 138:959-964

91. Lingegowda V, Van QC, Shimada M, Beaver TM, Dass B, Sood P, Ejaz AA: Longterm outcome of patients treated with prophylactic nesiritide for the prevention of acute kidney injury following cardiovascular surgery. Clin Cardiol 2010, 33:217-221.

92. Karlowicz MG, Adelman RD: Nonoliguric and oliguric acute renal failure in asphyxiated term neonates. Pediatr Nephrol 1995, 9:718-722.

93. Gouyon JB, Guignard JP: Theophylline prevents the hypoxemia-induced renal hemodynamic changes in rabbits. Kidney Int 1988, 33:1078-1083.

94. Bakr AF: Prophylactic theophylline to prevent renal dysfunction in newborns exposed to perinatal asphyxia - a study in a developing country. Pediatr Nephrol 2005, 20:1249-1252.

95. Bhat MA, Shah ZA, Makhdoomi MS, Mufti MH: Theophylline for renal function in term neonates with perinatal asphyxia: a randomized, placebo-controlled trial. J Pediatr 2006, 149:180-184.

96. Jenik AG, Ceriani Cernadas JM, Gorenstein A, Ramirez JA, Vain N, Armadans M, Ferraris JR: A randomized, double-blind, placebo-controlled trial of the effects of prophylactic theophylline on renal function in term neonates with perinatal asphyxia. Pediatrics 2000, 105:E45.

97. Cattarelli D, Spandrio M, Gasparoni A, Bottino R, Offer C, Chirico G: A randomised, double blind, placebo controlled trial of the effect of theophylline in prevention of vasomotor nephropathy in very preterm neonates with respiratory distress syndrome. Arch Dis Child Fetal Neonatal Ed 2006, 91:F80-F84. 
98. Massie BM, O'Connor CM, Metra M, Ponikowski P, Teerlink JR, Cotter G, Weatherley BD, Cleland JG, Givertz MM, Voors A, DeLucca P, Mansoor GA, Salerno CM, Bloomfield DM, Dittrich HC; PROTECT Investigators and Committees: Rolofylline, an adenosine A1-receptor antagonist, in acute heart failure. NEngl J Med 2010, 363:1419-1428.

99. Franklin SC, Moulton M, Sicard GA, Hammerman MR, Miller SB: Insulin-like growth factor I preserves renal function postoperatively. Am J Physiol 1997, 272(2 Pt 2):F257-F259.

100. Hirschberg R, Kopple J, Lipsett P, Benjamin E, Minei J, Albertson T, Munger M, Metzler M, Zaloga G, Murray M, Lowry S, Conger J, McKeown W, O'shea M, Baughman R, Wood K, Haupt M, Kaiser R, Simms H, Warnock D, Summer W, Hintz R, Myers B, Haenftling K, Capra W, Pike M, Guler H-P: Multicenter clinical trial of recombinant human insulin-like growth factor I in patients with acute renal failure. Kidney Int 1999, 55:2423-2432.

101. Hladunewich MA, Corrigan G, Derby GC, Ramaswamy D, Kambham N, Scandling JD, Myers BD: A randomized, placebo-controlled trial of IGF-1 for delayed graft function: a human model to study postischemic ARF. Kidney Int 2003, 64:593-602.

102. Zahar JR, Rioux C, Girou E, Hulin A, Sauve C, Bernier-Combes A, Brun-Buisson C, Lesprit P: Inappropriate prescribing of aminoglycosides: risk factors and impact of an antibiotic control team. J Antimicrob Chemother 2006, 58:651-656.

103. Bliziotis IA, Michalopoulos A, Kasiakou SK, Samonis G, Christodoulou C, Chrysanthopoulou S, Falagas ME: Ciprofloxacin vs an aminoglycoside in combination with a beta-lactam for the treatment of febrile neutropenia: a meta-analysis of randomized controlled trials. Mayo Clin Proc 2005, 80:1146-1156.

104. Cosgrove SE, Vigliani GA, Fowler VG, Jr, Abrutyn E, Corey GR, Levine DP, Rupp $\mathrm{ME}$, Chambers HF, Karchmer AW, Boucher HW: Initial low-dose gentamicin for Staphylococcus aureus bacteremia and endocarditis is nephrotoxic. Clin Infect Dis 2009, 48:713-721.

105. Falagas ME, Matthaiou DK, Bliziotis IA: The role of aminoglycosides in combination with a beta-lactam for the treatment of bacterial endocarditis: a meta-analysis of comparative trials. J Antimicrob Chemother 2006, 57:639-647.

106. Falagas ME, Matthaiou DK, Karveli EA, Peppas G: Meta-analysis: randomized controlled trials of clindamycin/aminoglycoside vs. beta-lactam monotherapy for the treatment of intra-abdominal infections. Aliment Pharmacol Ther 2007, 25:537-556.

107. Glasmacher A, von Lilienfeld-Toal M, Schulte S, Hahn C, Schmidt-Wolf IG, Prentice A: An evidence-based evaluation of important aspects of empirical antibiotic therapy in febrile neutropenic patients. Clin Microbiol Infect 2005, 11(Suppl 5):17-23.

108. Paul M, Benuri-Silbiger I, Soares-Weiser K, Leibovici L: Beta lactam monotherapy versus beta lactam-aminoglycoside combination therapy for sepsis in immunocompetent patients: systematic review and metaanalysis of randomised trials. BMJ 2004, 328:668.

109. Paul M, Silbiger I, Grozinsky S, Soares-Weiser K, Leibovici L: Beta lactam antibiotic monotherapy versus beta lactam-aminoglycoside antibiotic combination therapy for sepsis. Cochrane Database Syst Rev 2006, 1:CD003344.

110. Baciewicz AM, Sokos DR, Cowan Rl: Aminoglycoside-associated nephrotoxicity in the elderly. Ann Pharmacother 2003, 37:182-186.

111. Barclay ML, Kirkpatrick CM, Begg EJ: Once daily aminoglycoside therapy. Is it less toxic than multiple daily doses and how should it be monitored? Clin Pharmacokinet 1999, 36:89-98.

112. Graham AC, Mercier RC, Achusim LE, Pai MP: Extended-interval aminoglycoside dosing for treatment of enterococcal and staphylococcal osteomyelitis. Ann Pharmacother 2004, 38:936-941.

113. Kiel PJ, Lo M, Stockwell D, Patel GP: An evaluation of amikacin nephrotoxicity in the hematology/oncology population. Am J Ther 2008, 15:131-136.

114. Kraus DM, Pai MP, Rodvold KA: Efficacy and tolerability of extended-interval aminoglycoside administration in pediatric patients. Paediatr Drugs 2002 4:469-484.

115. Nestaas E, Bangstad HJ, Sandvik L, Wathne KO: Aminoglycoside extended interval dosing in neonates is safe and effective: a meta-analysis. Arch Dis Child Fetal Neonatal Ed 2005, 90:F294-F300.

116. Peloquin CA, Berning SE, Nitta AT, Simone PM, Goble M, Huitt GA, Iseman MD, Cook JL, Curran-Everett D: Aminoglycoside toxicity: daily versus thriceweekly dosing for treatment of mycobacterial diseases. Clin Infect Dis 2004 ,
38:1538-1544

117. Peters-Volleberg GW, Dortant PM, Speijers GJ: Comparison of tobramycin nephrotoxicity in young adult and aged female rats. Pharmacol Toxicol 1999, 84:147-153.

118. Rougier F, Claude D, Maurin M, Sedoglavic A, Ducher M, Corvaisier S, Jelliffe R, Maire P: Aminoglycoside nephrotoxicity: modeling, simulation, and control. Antimicrob Agents Chemother 2003, 47:1010-1016.

119. Rougier F, Ducher M, Maurin M, Corvaisier S, Claude D, Jelliffe R, Maire P: Aminoglycoside dosages and nephrotoxicity: quantitative relationships. Clin Pharmacokinet 2003, 42:493-500.

120. Rybak MJ, Abate BJ, Kang SL, Ruffing MJ, Lerner SA, Drusano GL: Prospective evaluation of the effect of an aminoglycoside dosing regimen on rates of observed nephrotoxicity and ototoxicity. Antimicrob Agents Chemother 1999, 43:1549-1555.

121. Smyth $A R$, Tan $K H$ : Once-daily versus multiple-daily dosing with intravenous aminoglycosides for cystic fibrosis. Cochrane Database Syst Rev 2006, 3:CD002009.

122. Ali MZ, Goetz MB: A meta-analysis of the relative efficacy and toxicity of single daily dosing versus multiple daily dosing of aminoglycosides. Clin Infect Dis 1997, 24:796-809.

123. Bailey TC, Little JR, Littenberg B, Reichley RM, Dunagan WC: A meta-analysis of extended-interval dosing versus multiple daily dosing of aminoglycosides. Clin Infect Dis 1997, 24:786-795.

124. Barza M, loannidis JP, Cappelleri JC, Lau J: Single or multiple daily doses of aminoglycosides: a meta-analysis. BMJ 1996, 312:338-345

125. Ferriols-Lisart R, Alos-Alminana M: Effectiveness and safety of once-daily aminoglycosides: a meta-analysis. Am J Health Syst Pharm 1996, 53:1141-1150

126. Hatala R, Dinh T, Cook DJ: Once-daily aminoglycoside dosing in immunocompetent adults: a meta-analysis. Ann Intern Med 1996, 124:717-725.

127. Munckhof WJ, Grayson ML, Turnidge JD: A meta-analysis of studies on the safety and efficacy of aminoglycosides given either once daily or as divided doses. J Antimicrob Chemother 1996, 37:645-663.

128. Cannella CA, Wilkinson ST: Acute renal failure associated with inhaled tobramycin. Am J Health Syst Pharm 2006, 63:1858-1861

129. Izquierdo MJ, Gomez-Alamillo C, Ortiz F, Calabia ER, Ruiz JC, de Francisco AL, Arias M: Acute renal failure associated with use of inhaled tobramycin for treatment of chronic airway colonization with Pseudomonas aeruginosa. Clin Nephrol 2006, 66:464-467.

130. Alexander BD, Wingard JR: Study of renal safety in amphotericin B lipid complex-treated patients. Clin Infect Dis 2005, 40(Suppl 6):S414-S421.

131. Cornely OA, Maertens J, Bresnik M, Ebrahimi R, Ullmann AJ, Bouza E, Heussel CP, Lortholary O, Rieger C, Boehme A, Aoun M, Horst HA, Thiebaut A, Ruhnke M, Reichert D, Vianelli N, Krause SW, Olavarria E, Herbrecht R; AmBiLoad Trial Study Group: Liposomal amphotericin B as initial therapy for invasive mold infection: a randomized trial comparing a high-loading dose regimen with standard dosing (AmBiLoad trial). Clin Infect Dis 2007, 44:1289-1297.

132. Garbino J, Adam A: Use of high-dose liposomal amphotericin B: efficacy and tolerance. Acta Biomed 2006, 77(Suppl 4):19-22

133. Girois SB, Chapuis F, Decullier E, Revol BG: Adverse effects of antifungal therapies in invasive fungal infections: review and meta-analysis. Eur $J$ Clin Microbiol Infect Dis 2005, 24:119-130.

134. Hachem RY, Boktour MR, Hanna HA, Husni RN, Torres HA, Afif C, Kontoyiannis DP, Raad, II: Amphotericin B lipid complex versus liposomal amphotericin B monotherapy for invasive aspergillosis in patients with hematologic malignancy. Cancer 2008, 112:1282-1287.

135. Johansen HK, Gotzsche PC: Amphotericin B lipid soluble formulations vs. amphotericin B in cancer patients with neutropenia. Cochrane Database Syst Rev 2000, 3:CD000969.

136. Johnson PC, Wheat LJ, Cloud GA, Goldman M, Lancaster D, Bamberger DM, Powderly WG, Hafner R, Kauffman CA, Dismukes WE: Safety and efficacy of liposomal amphotericin B compared with conventional amphotericin B for induction therapy of histoplasmosis in patients with AIDS. Ann Intern Med 2002, 137:105-109.

137. Kleinberg $\mathrm{M}$ : What is the current and future status of conventional amphotericin B? Int J Antimicrob Agents 2006, 27(Suppl 1):12-16.

138. Olson JA, Adler-Moore JP, Schwartz J, Jensen GM, Proffitt RT: Comparative efficacies, toxicities, and tissue concentrations of amphotericin B lipid formulations in a murine pulmonary aspergillosis model. Antimicrob Agents Chemother 2006, 50:2122-2131. 
139. Saliba F, Dupont B: Renal impairment and amphotericin B formulations in patients with invasive fungal infections. Med Mycol 2008, 46:97-112.

140. Ullmann AJ, Sanz MA, Tramarin A, Barnes RA, Wu W, Gerlach BA, Krobot KJ, Gerth WC: Prospective study of amphotericin B formulations in immunocompromised patients in 4 European countries. Clin Infect Dis 2006, 43:e29-e38.

141. Veerareddy PR, Vobalaboina V: Lipid-based formulations of amphotericin B. Drugs Today (Barc) 2004, 40:133-145

142. Walsh TJ, Finberg RW, Arndt C, Hiemenz J, Schwartz C, Bodensteiner D, Pappas P, Seibel N, Greenberg RN, Dummer S, Schuster M, Holcenberg JS: Liposomal amphotericin B for empirical therapy in patients with persistent fever and neutropenia. National Institute of Allergy and Infectious Diseases Mycoses Study Group. N Engl J Med 1999, 340:764-771.

143. Boogaerts M, Winston DJ, Bow EJ, Garber G, Reboli AC, Schwarer AP, Novitzky $\mathrm{N}$, Boehme A, Chwetzoff E, De Beule K: Intravenous and oral itraconazole versus intravenous amphotericin $B$ deoxycholate as empirical antifungal therapy for persistent fever in neutropenic patients with cancer who are receiving broad-spectrum antibacterial therapy. A randomized, controlled trial. Ann Intern Med 2001, 135:412-422.

144. Johansen HK, Gotzsche PC: Amphotericin B versus fluconazole for controlling fungal infections in neutropenic cancer patients. Cochrane Database Syst Rev 2002, 2:CD000239.

145. Park SH, Choi SM, Lee DG, Choi JH, Yoo JH, Min WS, Shin WS: Intravenous itraconazole vs. amphotericin B deoxycholate for empirical antifungal therapy in patients with persistent neutropenic fever. Korean J Intern Med 2006, 21:165-172.
146. Raad, II, Hanna HA, Boktour M, Jiang Y, Torres HA, Afif C, Kontoyiannis DP, Hachem RY: Novel antifungal agents as salvage therapy for invasive aspergillosis in patients with hematologic malignancies: posaconazole compared with high-dose lipid formulations of amphotericin B alone or in combination with caspofungin. Leukemia 2008, 22:496-503.

147. Wegner B, Baer P, Gauer S, Oremek G, Hauser IA, Geiger H: Caspofungin is less nephrotoxic than amphotericin $B$ in vitro and predominantly damages distal renal tubular cells. Nephrol Dial Transplant 2005, 20:2071-2079.

148. Seabra VF, Alobaidi S, Balk EM, Poon AH, Jaber BL: Off-pump coronary artery bypass surgery and acute kidney injury: a meta-analysis of randomized controlled trials. Clin J Am Soc Nephrol 2010, 5:1734-1744.

149. Ho KM, Morgan DJ: Meta-analysis of $N$-acetylcysteine to prevent acute renal failure after major surgery. Am J Kidney Dis 2009, 53:33-40.

150. Komisarof JA, Gilkey GM, Peters DM, Koudelka CW, Meyer MM, Smith SM: $\mathrm{N}$-acetylcysteine for patients with prolonged hypotension as prophylaxis for acute renal failure (NEPHRON). Crit Care Med 2007, 35:435-441.

doi:10.1186/cc11454

Cite this article as: Kellum JA, et al:: Diagnosis, evaluation, and management of acute kidney injury: a KDIGO summary (Part 1). Critical Care 2013, 17:204 